\title{
Speed Estimation of Direct Torque Control Permanent Magnet Synchronous Motor Drive Based on Back Electromotive Force
}

\author{
Yung-Chang Luo, ${ }^{*}$ Song-Yi Xie, Chia-Hung Lin, and Ying-Piao Kuo \\ Department of Electrical Engineering, National Chin-Yi University of Technology, \\ No. 57, Sec. 2, Zhongshan Rd, Taiping Dist., Taichung 41170, Taiwan (ROC)
}

(Received June 16, 2020; accepted October 21, 2020)

Keywords: speed estimation, direct torque control (DTC), permanent magnet synchronous motor (PMSM) drive, modified particle swarm optimization (PSO), voltage space vector pulse width modulation (VSVPWM)

A speed estimation scheme based on the back electromotive force (back-EMF) of motors was developed for a direct torque control (DTC) permanent magnet synchronous motor (PMSM) drive. The DTC PMSM drive was established using stator flux and electromagnetic torque. Three-phase stator currents and voltages were utilized to develop a rotor position estimator on the basis of back-EMF. The estimated rotor speed was derived from the rotor position estimator. Hall effect current sensors were used as an electromagnetic sensing element to obtain the stator current from the DTC PMSM under loading. Voltage space vector pulse width modulation (VSVPWM) was utilized to establish a voltage source inverter (VSI) in place of the traditional switching table (ST) VSI to reduce the ripples of the stator current and electromagnetic torque. A speed controller was designed using a modified particle swarm optimization (PSO) algorithm to achieve rapid convergence, low operational cost, and good applicability under various conditions. The MATLAB/Simulink ${ }^{(}{ }^{(}$toolbox was used to establish the simulation scheme, and all the control algorithms were realized on a control card (Texas Instruments TI DSP 6713-and-F2812). Simulation and experimental results (including the estimated rotor speed, stator current, estimated electromagnetic torque, and stator flux locus) confirmed the effectiveness of the proposed approach.

\section{Introduction}

Meeting the demand for energy saving and intelligent production requires superior drives and high-efficiency motors to actuate machinery. The permanent magnet synchronous motor (PMSM) is widely used in modem industries because of its reliability, low noise, high power density, high efficiency, and small size. Relative to field-orientation-controlled alternating current (AC) motor drives, AC motor drives based on the direct torque control (DTC) scheme achieve a quick response, exhibit a simple structure, and eliminate the need for decoupling computation. According to the DTC theory of AC motors, the torque and stator flux are directly modulated by individual controllers, and the suitable switching patterns of a voltage source inverter (VSI) are then selected to actuate the $\mathrm{AC}$ motor. ${ }^{(1)}$ Under an independent control condition, the torque and "Corresponding author: e-mail: luoyc@ncut.edu.tw https://doi.org/10.18494/SAM.2021.3019 
stator flux control loops show DTC inherent decoupling. Conventional closed-loop DTC PMSM drives require rotor position sensors, such as analog resolvers or digital encoders, to detect shaft positions; however, with such sensors, the robustness of PMSM drives is reduced, rendering them unsuitable for hostile environments. Hence, the development of speed estimation methods for DTC PMSM drives, as alternatives to conventional speed feedback methods, is required. Several speed estimation methods have been developed for PMSM drives; examples include the speed adjustment mechanism developed via model reference adaptive control, ${ }^{(2-4)}$ speed identification derived from an extended Kalman filter, ${ }^{(5-7)}$ speed estimation dependent on a flux observer or the back electromotive force (back-EMF) of a PMSM, ${ }^{(8-11)}$ and speed determination using fuzzy logic control or neural networks. ${ }^{(12-14)}$ In the current research, voltage space vector pulse width modulation (VSVPWM) was utilized to establish the VSI in place of a traditional switching table (ST) VSI to reduce the ripples of the stator current and electromagnetic torque. Three-phase stator voltages and currents were used to develop a rotor position estimator, from which the rotor speed was estimated. The three-phase stator currents were obtained from a PMSM using Hall effect current sensors. In the proposed speed estimation for DTC PMSM drives, a speed controller was devised using a modified particle swarm optimization (PSO) algorithm to achieve rapid convergence, low operational cost, and good applicability under various conditions. ${ }^{(15)}$

This paper comprises six sections. Section 1 presents the research motivation, background, and literature review on speed estimation methods for DTC PMSM drives. Section 2 describes the DTC PMSM drive based on the VSVPWM strategy. Section 3 discusses the speed estimation scheme based on back-EMF. Section 4 details the design of the speed controller based on a modified PSO algorithm. Sections 5 and 6 cover the experimental setup and results, the discussion, and the conclusion.

\section{VSVPWM-based DTC PMSM Drive}

Suppose a permanent magnet is arranged on the surface of a rotor without damping winding, which can be regarded as an equivalent current source. The permanent magnet's axis coincides with the d-axis of the rotor shaft. The stator voltage vector equation of a PMSM in the synchronous reference coordinate frame is given by ${ }^{(16)}$

$$
R_{s} \vec{i}_{s}^{e}+L_{s} p \vec{i}_{s}^{e}+j \omega_{e} L_{s} \vec{i}_{s}^{e}+j \omega_{e} \lambda_{F}=\vec{v}_{s}^{e},
$$

where $j$ is the imaginary unit; $\vec{i}_{s}^{e}=i_{d s}^{e}+j i_{q s}^{e}$ and $\vec{v}_{s}^{e}=v_{d s}^{e}+j v_{q s}^{e}$ are the current and voltage vectors of the stator, respectively; $R_{S}$ and $L_{S}$ are the resistance and inductance of the stator, respectively; $\lambda_{F}$ is the equivalent rotor magnet flux produced by the permanent magnet of the rotor; $\omega_{e}$ is the speed of the synchronous reference coordinate frame; and $p$ is the differential operator. 


\subsection{DTC PMSM drive}

Under a DTC condition, the estimated stator flux in the stationary reference coordinate $\left(\omega_{e}=0\right)$ frame is given by ${ }^{(16)}$

$$
\hat{\vec{\lambda}}_{s}^{s}=\frac{\tau_{c}}{1+s \tau_{c}}\left(\vec{v}_{s}^{s}-R_{s} \vec{i}_{s}^{s}\right)+\frac{1}{1+s \tau_{c}} \vec{\lambda}_{s}^{s *}
$$

where the symbol $\wedge$ indicates an estimated value, $s$ is the Laplace operator, $\tau_{c}$ is the time constant of the low-pass filter, and $\vec{\lambda}_{s}^{s^{*}}$ is the reference command of the stator flux.

The estimated synchronous position angle required to achieve the VSVPWM DTC strategy is acquired using the $d$-axis- and $q$-axis-estimated stator flux from

$$
\hat{\theta}_{e}=\tan ^{-1}\left(\frac{\hat{\lambda}_{q s}^{s}}{\hat{\lambda}_{d s}^{s}}\right) .
$$

The generated electromagnetic torque of a PMSM under a DTC condition is given by

$$
T_{e}=\frac{3 P}{4}\left(\hat{\lambda}_{d s}^{s} i_{q s}^{s}-\hat{\lambda}_{q s}^{s} i_{d s}^{s}\right)
$$

where $P$ is the pole number of the motor. The mechanical equation of the motor is acquired as

$$
B_{m} \omega_{r m}+J_{m} p \omega_{r m}=T_{e}-T_{L}
$$

where $B_{m}$ and $J_{m}$ are the viscous friction coefficient and inertia of the PMSM, respectively; $T_{L}$ is the load torque; and $\omega_{r m}=(2 / P) \omega_{r}$ is the mechanical speed of the PMSM shaft.

\subsection{VSVPWM design strategy}

According to the best strategy of pulse width modulation, (1) the switching period should be kept as short as possible; and (2) the minimum deviation of the current should be maintained during several switching states. ${ }^{(17)}$ The design procedure for VSVPWM must also follow the best PWM strategy.

Under the conventional VSVPWM strategy, the voltage space vector plane is divided into six sectors $\left(S_{1}, S_{2}, \ldots, S_{6}\right)$, and these sectors are composed of six nonzero voltage vectors $\left(V_{1}, V_{2}, \ldots, V_{6}\right)$ and two zero voltage vectors $\left(V_{0}, V_{7}\right)$ of a VSI. According to the sector position of a specific reference voltage vector $\left(V_{r e f}\right)$, the specific reference voltage vector is composed of two adjacent nonzero voltage vectors and two zero voltage vectors (based on the minimum switching states). The voltage space vector plane based on VSVPWM is shown in Fig. 1. Here, $V_{x}(a, b, c), x=0, \ldots, 7$ is the switching state of a three-phase VSI, "1" stands for the upper-arm 


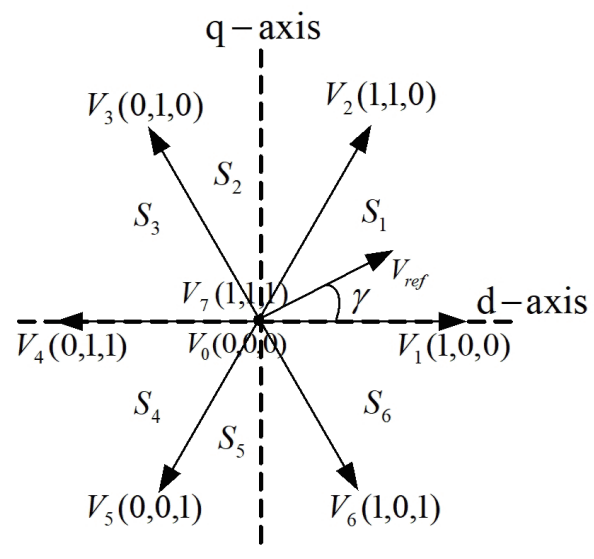

Fig. 1. Voltage space vector plane of VSVPWM.

switch of the three-phase VSI to be switched ON, and "0" stands for the lower-arm switch of the three-phase VSI to be switched ON.

Under the best VSVPSM strategy, the voltage vector needs to start from a zero voltage vector and end at another zero voltage vector during each switching period. In sector 1 , the specific reference voltage vector is composed of a sequence of $\ldots, V_{0}, V_{1}, V_{2}, V_{7}, V_{2}, V_{1}, V_{0}, \ldots$ during each sampling period (one sampling period is composed of two switching periods). The specific reference voltage vector at a switching period in sector 1 is given by

$$
\int_{0}^{T_{z}} V_{r e f} d t=\int_{0}^{T_{1}} V_{1} d t+\int_{T_{1}}^{T_{1}+T_{2}} V_{2} d t+\int_{T_{1}+T_{2}}^{T_{z}} V_{0} d t, T_{z}-\left(T_{1}+T_{2}\right)=2 T_{0}, T_{7}=T_{0},
$$

where $T_{z}$ is the switching period; $T_{1}$ is the action time of $V_{1} ; T_{2}$ is the action time of $V_{2}$; and the action times $T_{0}$ and $T_{7}$ of $V_{0}$ and $V_{7}$, respectively. If the switching period is sufficiently short, then $V_{\text {ref }}$ can be regarded as a constant value during a switching period. With $V_{1}$ and $V_{2}$ constant, the magnitude of $V_{0}$ and $V_{7}$ is zero. Then, Eq. (6) can be modified as

$$
T_{1} \cdot V_{1}+T_{2} \cdot V_{2}=T_{z} \cdot V_{r e f}
$$

where $T_{z}=1 /\left(2 f_{s}\right)$ and $f_{s}$ is the sampling frequency. In the two-axis coordinate $(d-q)$ frame, Eq. (7) is expressed as

$$
T_{1}\left[\begin{array}{l}
1 \\
0
\end{array}\right]+T_{2}\left[\begin{array}{c}
\cos (\pi / 3) \\
\sin (\pi / 3)
\end{array}\right]=a \cdot T_{z}\left[\begin{array}{c}
\cos \gamma \\
\sin \gamma
\end{array}\right]
$$

where $a=\left|V_{\text {ref }}\right| /\left[(2 / 3) V_{d c}\right], V_{d c}$ is the DC bus voltage, $\gamma$ is the angle between $V_{\text {ref }}$ and $V_{1}$, and $0 \leq \gamma \leq \pi / 3$. The first and second rows of Eq. (8) can be derived respectively as 


$$
\begin{gathered}
T_{1}+T_{2} \cos (\pi / 3)=a \cdot T_{c} \cdot \cos \gamma, \\
T_{2} \sin (\pi / 3)=a \cdot T_{c} \cdot \sin \gamma .
\end{gathered}
$$

From Eqs. (9) and (10), the action times for $T_{1}, T_{2}, T_{0}$, and $T_{7}$ are derived as

$$
\begin{gathered}
T_{1}=a \cdot T_{z} \cdot \frac{\sin (\pi / 3-\gamma)}{\sin (\pi / 3)}, \\
T_{2}=a \cdot T_{z} \cdot \frac{\sin \gamma}{\sin (\pi / 3)}, \\
T_{0}=T_{7}=\frac{1}{2}\left(T_{z}-T_{1}-T_{2}\right) .
\end{gathered}
$$

The best pulse form of VSVPWM in sector 1 is shown in Fig. 2, where $V_{a}, V_{b}$, and $V_{c}$ denote the three-phase voltages and $V_{q}=(1 / 2) V_{d c}$. This waveform is symmetrical about the central axis and allows the current harmonic and torque pulsation to be reduced.

According to Fig. 2, the three-phase mean voltages to the neutral point for a switching period in sector 1 can be derived as

$$
\bar{V}_{a}=\frac{V_{q}}{T_{z}}\left(-\frac{T_{0}}{2}+T_{1}+T_{2}+\frac{T_{0}}{2}\right)=\frac{2}{\sqrt{3}} \cdot a \cdot V_{q} \sin \left(\gamma+\frac{\pi}{3}\right)
$$

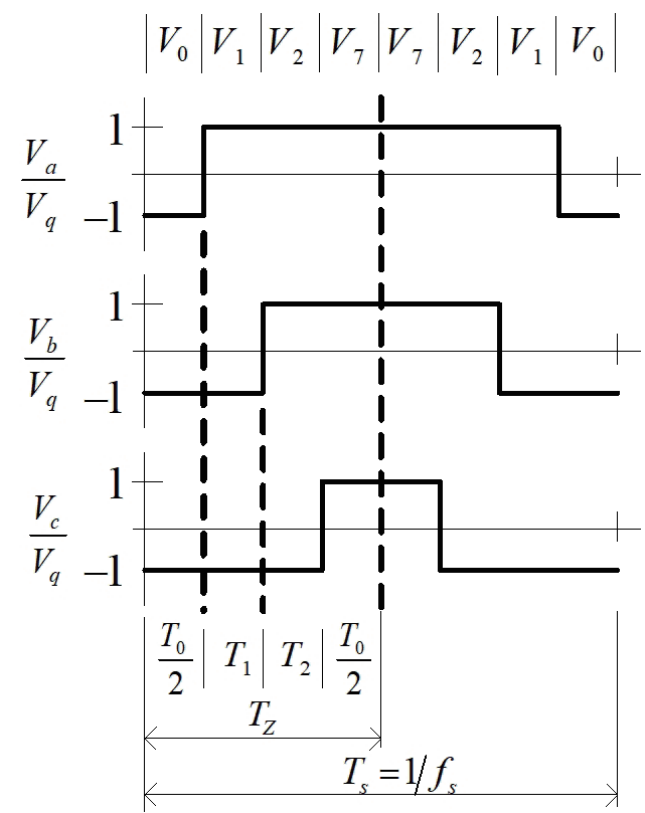

Fig. 2. Best pulse form of VSVPWM in sector 1. 


$$
\begin{gathered}
\bar{V}_{b}=\frac{V_{q}}{T_{z}}\left(-\frac{T_{0}}{2}-T_{1}+T_{2}+\frac{T_{0}}{2}\right)=2 \cdot a \cdot V_{q} \sin \left(\gamma-\frac{\pi}{6}\right), \\
\bar{V}_{c}=\frac{V_{q}}{T_{z}}\left(-\frac{T_{0}}{2}-T_{1}-T_{2}+\frac{T_{0}}{2}\right)=-\bar{V}_{a} .
\end{gathered}
$$

The best VSVPSM for sectors 2 to 6 can also be derived similarly to that for sector 1 . The designed three-phase reference phase voltage waveforms and three-phase reference line voltage waveforms are shown in Figs. 3 and 4, respectively.

\section{Speed Estimation Based on Back-EMF of PMSM}

In the proposed speed estimation of DTC PMSM drives, the estimated rotor speed is derived from the back-EMF of a PMSM. ${ }^{(18)}$ The three-phase stator voltage equation of a PMSM is given by

$$
\left[\begin{array}{l}
v_{a s} \\
v_{b s} \\
v_{c s}
\end{array}\right]=\left[\begin{array}{ccc}
R_{s} & 0 & 0 \\
0 & R_{s} & 0 \\
0 & 0 & R_{s}
\end{array}\right]\left[\begin{array}{c}
i_{a s} \\
i_{b s} \\
i_{c s}
\end{array}\right]+\left[\begin{array}{ccc}
L_{s l} & 0 & 0 \\
0 & L_{s l} & 0 \\
0 & 0 & L_{s l}
\end{array}\right] p\left[\begin{array}{c}
i_{a s} \\
i_{b s} \\
i_{c s}
\end{array}\right]+\left[\begin{array}{c}
E_{a s} \\
E_{b s} \\
E_{c s}
\end{array}\right],
$$

where $v_{a s}, v_{b s}$, and $v_{c s}$ are the three-phase stator voltages; $i_{a s}, i_{b s}$, and $i_{c s}$ are the threephase stator currents; $E_{a s}, E_{b s}$, and $E_{c s}$ are the three-phase stator back-EMFs of the PMSM; $L_{s l}=L_{s}-L_{m}$ is the stator leakage inductance; and $L_{m}$ is the mutual inductance. The three-phase stator back-EMF can be expressed as
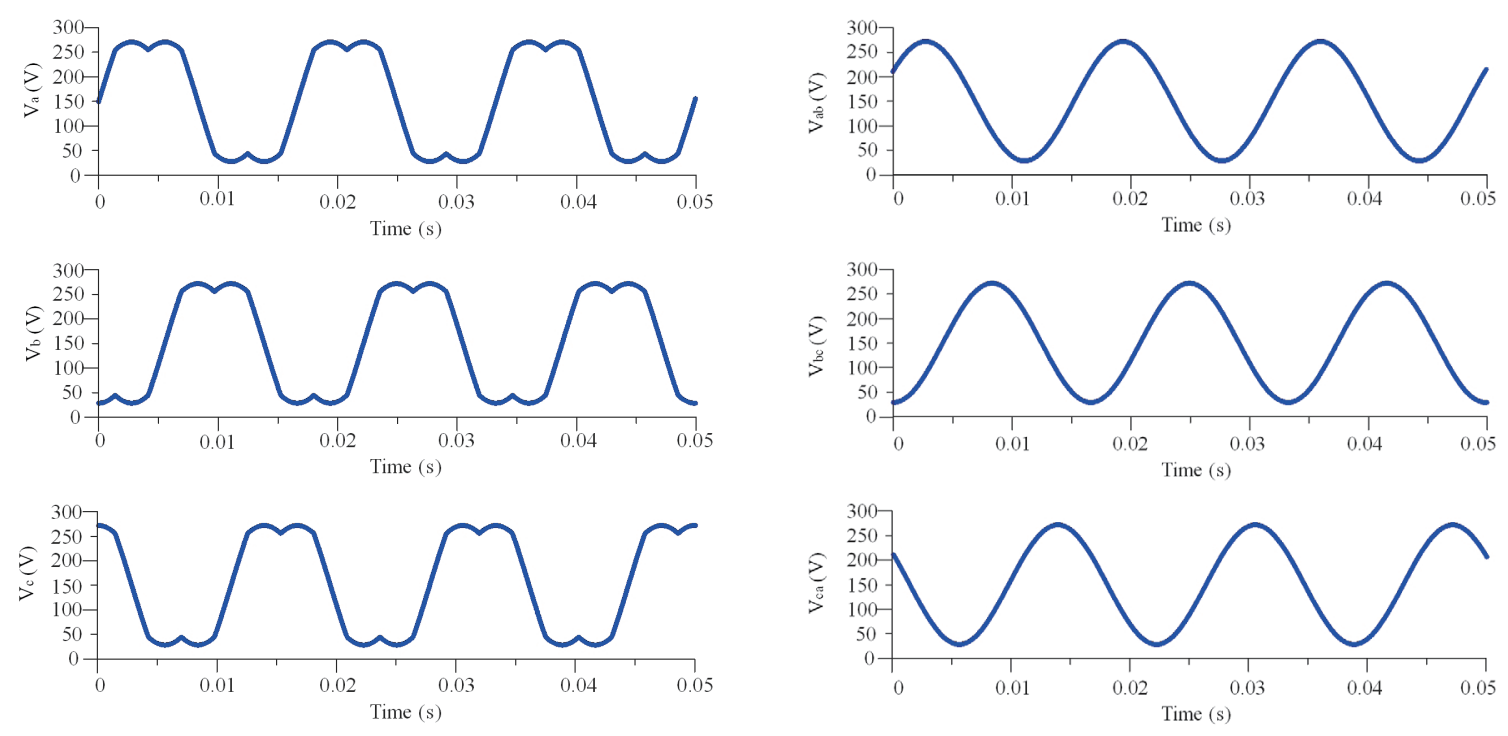

Fig. 3. (Color online) Three-phase reference phase voltage waveforms for VSVPWM.

Fig. 4. (Color online) Three-phase reference line voltage waveforms for VSVPWM. 


$$
\left[\begin{array}{c}
E_{a s} \\
E_{b s} \\
E_{c s}
\end{array}\right]=\left[\begin{array}{c}
K_{e} \omega_{r} e_{a s}\left(\theta_{e}\right) \\
K_{e} \omega_{r} e_{b s}\left(\theta_{e}\right) \\
K_{e} \omega_{r} e_{c s}\left(\theta_{e}\right)
\end{array}\right],
$$

where $e_{a s}\left(\theta_{e}\right), e_{b s}\left(\theta_{e}\right)$, and $e_{c s}\left(\theta_{e}\right)$ are the three-phase instantaneous stator back-EMFs of the PMSM, $K_{e}$ is the back-EMF constant, and $\theta_{e}=(P / 2) \int \omega_{r m} d t$ is the synchronous position angle. By substituting Eq. (18) into Eq. (17) and by defining the function $d f(\cdot) / d t=\Delta f(\cdot) / \Delta t$, the increment of the synchronous position angle is derived as ${ }^{(18)}$

$$
\left[\begin{array}{c}
\Delta \theta_{a e} \\
\Delta \theta_{b e} \\
\Delta \theta_{c e}
\end{array}\right]=\frac{P}{2 K_{e}}\left[\begin{array}{l}
\frac{\left(v_{a s}-R_{s} i_{a s}\right) \Delta t-L_{s l} \Delta i_{a s}}{e_{a s}\left(\theta_{e}\right)} \\
\frac{\left(v_{b s}-R_{s} i_{b s}\right) \Delta t-L_{s l} \Delta i_{b s}}{e_{b s}\left(\theta_{e}\right)} \\
\frac{\left(v_{c s}-R_{s} i_{c s}\right) \Delta t-L_{s l} \Delta i_{c s}}{e_{c s}\left(\theta_{e}\right)}
\end{array}\right],
$$

where $\Delta t$ is the sampling interval and $\Delta i_{a s}, \Delta i_{b s}$, and $\Delta i_{c s}$ are the three-phase stator current increments in the sampling interval. Equation (19) can also be expressed as

$$
\left[\begin{array}{c}
\Delta \theta_{a e} \\
\Delta \theta_{b e} \\
\Delta \theta_{c e}
\end{array}\right]=\frac{P}{2 K_{e}}\left[\begin{array}{c}
\frac{\Delta \lambda_{a s}}{e_{a s}\left(\theta_{e}\right)} \\
\frac{\Delta \lambda_{b s}}{e_{b s}\left(\theta_{e}\right)} \\
\frac{\Delta \lambda_{c s}}{e_{c s}\left(\theta_{e}\right)}
\end{array}\right]
$$

where $\Delta \lambda_{a s}, \Delta \lambda_{b s}$, and $\Delta \lambda_{c s}$ are the three-phase stator flux increments in a sampling interval. As indicated in Eq. (20), if the three-phase instantaneous stator back-EMFs reach a value of zero, then the synchronous position angle increases and diverges. This situation can be avoided by modifying Eq. (20) as ${ }^{(18)}$

$$
\left[\begin{array}{c}
\Delta \theta_{a e} e_{a s}\left(\theta_{e}\right) e_{b s}\left(\theta_{e}\right) \\
\Delta \theta_{b e} e_{b s}\left(\theta_{e}\right) e_{c s}\left(\theta_{e}\right) \\
\Delta \theta_{c e} e_{c s}\left(\theta_{e}\right) e_{a s}\left(\theta_{e}\right)
\end{array}\right]=\frac{P}{2 K_{e}}\left[\begin{array}{c}
\Delta \lambda_{a s} e_{b s}\left(\theta_{e}\right) \\
\Delta \lambda_{b s} e_{c s}\left(\theta_{e}\right) \\
\Delta \lambda_{c s} e_{a s}\left(\theta_{e}\right)
\end{array}\right] .
$$

The average increment of the electrical rotor position angle is given by 


$$
\Delta \theta_{e}=\frac{\Delta \theta_{a e}+\Delta \theta_{b e}+\Delta \theta_{c e}}{3} .
$$

According to Eqs. (20)-(22), the increment of the estimated electrical rotor position angle can be defined as ${ }^{(18)}$

$$
\Delta \hat{\theta}_{e}=\frac{P}{2 K_{e}} \frac{\Delta \lambda_{a s} e_{b s}\left(\hat{\theta}_{e}\right)+\Delta \lambda_{b s} e_{c s}\left(\hat{\theta}_{e}\right)+\Delta \lambda_{c s} e_{a s}\left(\hat{\theta}_{e}\right)}{e_{a s}\left(\hat{\theta}_{e}\right) e_{b s}\left(\hat{\theta}_{e}\right)+e_{b s}\left(\hat{\theta}_{e}\right) e_{c s}\left(\hat{\theta}_{e}\right)+e_{c s}\left(\hat{\theta}_{e}\right) e_{a s}\left(\hat{\theta}_{e}\right)} .
$$

Through discrete computation, the estimated electrical rotor position angle in the next sampling interval is derived as

$$
\hat{\theta}_{e}(n+1)=\hat{\theta}_{e}(n)+\Delta \hat{\theta}_{e}
$$

where $\hat{\theta}_{e}(n)$ and $\hat{\theta}_{e}(n+1)$ are the estimated electrical rotor position angles in the present and subsequent sampling intervals, respectively. The block diagram of the estimated rotor speed based on back-EMF is shown Fig. 5.

\section{Speed Controller Design Using Modified PSO Algorithm}

A modified PSO algorithm is used to design the speed controller of the proposed speed estimation method for DTC PMSM drives based on back-EMF. The modified PSO can rapidly search for the best solution in the initial stage and can achieve effective convergence in the later process. ${ }^{(19)}$ In the modified PSO algorithm, a periodic iterative computation is applied to update the velocity and position of each particle until the end condition is satisfied for the best solution. The updated velocity and position of the particle are given by

$$
v_{i}(n+1)=\beta \cdot v_{i}(n)+k_{1} \cdot \text { rand } \cdot\left(P_{b e s t}-x_{i}\right)+k_{2} \cdot \text { rand } \cdot\left(G_{\text {best }}-x_{i}\right),
$$

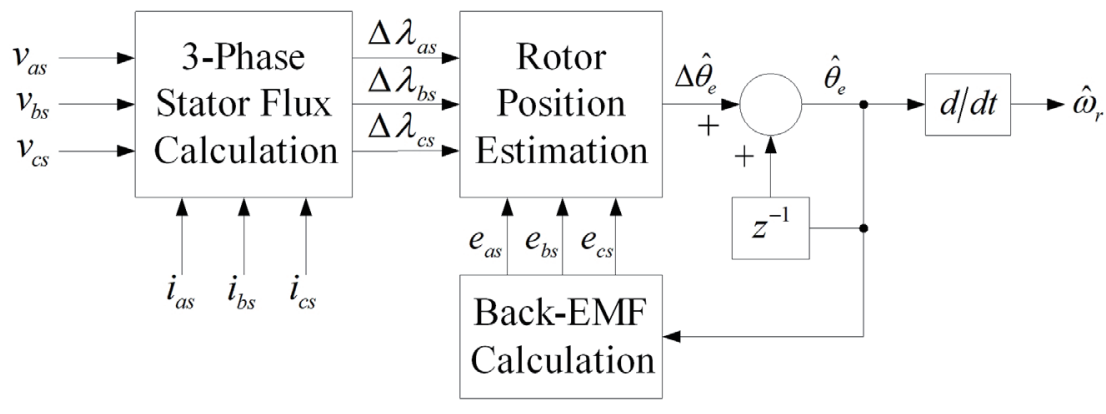

Fig. 5. Block diagram of estimated rotor speed based on back-EMF. 


$$
\begin{gathered}
v_{i}(n+1)=\left\{\begin{array}{ll}
v_{\text {min }}, & \text { if } v_{i}(n+1) \leq v_{\text {min }} \\
v_{\text {max }}, & \text { if } v_{i}(n+1) \geq v_{\text {max }}
\end{array},\right. \\
x_{i}(n+1)=x_{i}(n)+v_{i}(n+1), \\
x_{i}= \begin{cases}0.015 \cdot \text { rand }, & \text { if } x_{i} \leq x_{\text {min }} \\
x_{\text {max }} \cdot \text { rand }, & \text { if } x_{i} \geq x_{\text {max }}\end{cases}
\end{gathered}
$$

where $v_{i}(n)$ and $x_{i}(n)$ are the current velocity and position of the particle, respectively; $v_{i}(n+1)$ and $x_{i}(n+1)$ are the next velocity and position of the particle, respectively; $\beta$ is the weighting factor; $P_{\text {best }}$ and $G_{\text {best }}$ are the best positions of the individual particle and swarm, respectively; $k_{1}$ and $k_{2}$ are the learning factors of the individual particle and swarm, respectively; and rand $\in(0,1]$. vmin and vmax are the prescribed minimum and maximum velocities of the particle, respectively. $x_{\min }$ and $x_{\max }$ are the prescribed minimum and maximum positions of the particle, respectively. The flow chart of the proposed speed controller design based on the modified PSO algorithm is shown in Fig. 6.

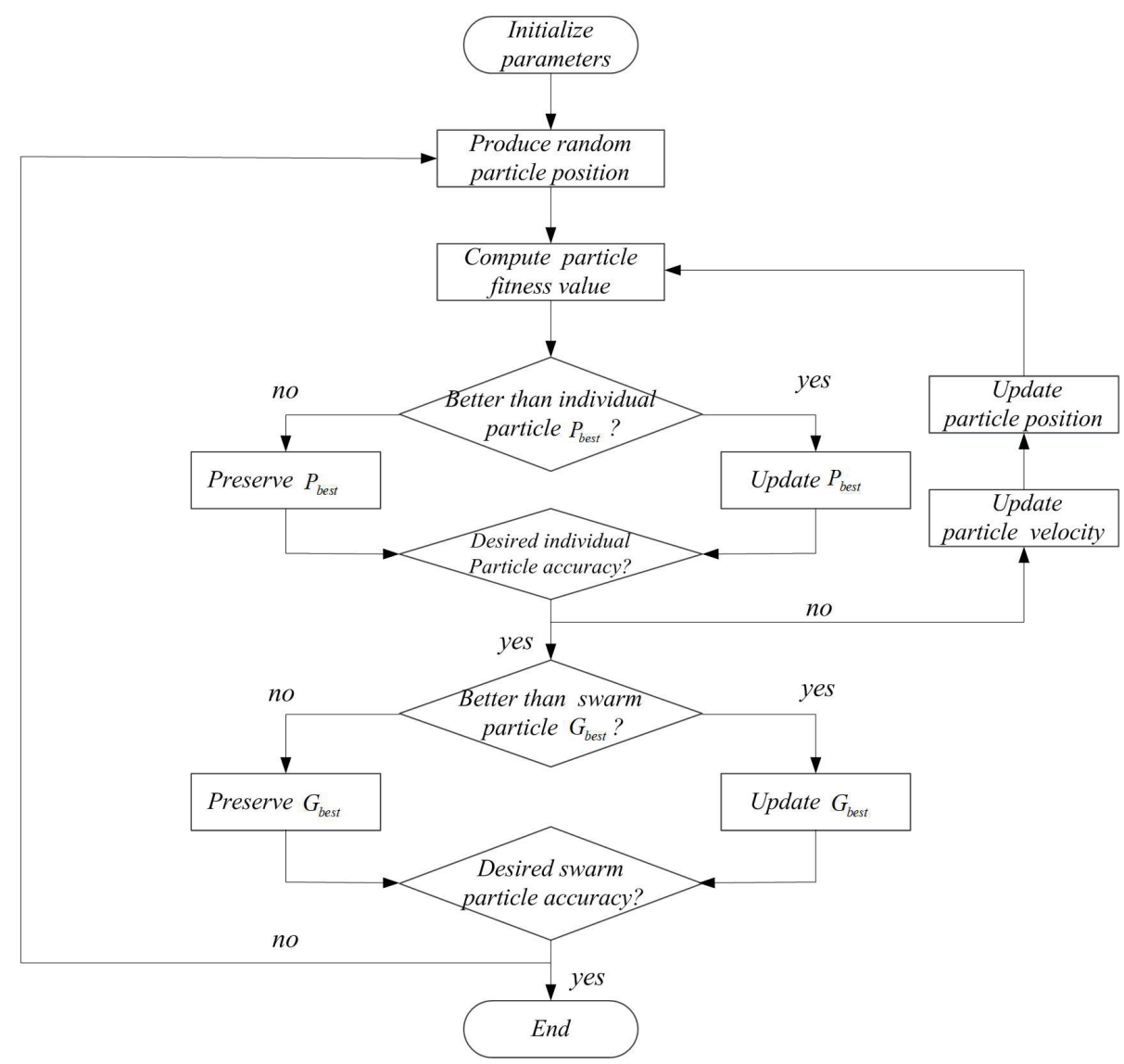

Fig. 6. Flow chart of proposed speed controller design based on modified PSO algorithm. 
A block diagram of the proposed speed estimation method for DTC PMSM drives based on back-EMF is shown in Fig. 7. The drive includes a speed controller, a torque controller, a flux controller, VSVPWM, torque calculation, stator flux $\hat{\lambda}_{s}$ and flux position angle $\hat{\theta}_{e}$ calculation, stationary coordinate transformation between the three phases and the two axes, and rotor speed estimation based on back-EMF. Here, the three-phase currents are obtained from the PMSM by using Hall effect current sensors.

In this system, proportion-integral (P-I)-type controllers for the flux and torque control loops are designed by the root locus method. The speed control loop is designed using the modified PSO algorithm. The proportion gain $\left(K_{p}\right)$, integral gain $\left(K_{i}\right)$, and bandwidth $(B W)$ for the two P-I-type controllers are shown in Table 1.

\section{Experimental Setup and Results}

A simulation scheme of the proposed system was established using the MATLAB/ Simulink ${ }^{\odot}$ toolbox. The implementation program was executed by a Texas Instruments DSP 6713-and-F2812 control card and a VSI to actuate the PMSM. A standard three-phase, $220 \mathrm{~V}$, $0.75 \mathrm{~kW}, \mathrm{Y}$-connected PMSM was used to confirm the effectiveness of the proposed speed estimation method for DTC PMSM drives based on back-EMF. In a running cycle, the sequence of speed commands was designed as follows: forward-direction acceleration from $t=0 \mathrm{~s}$ to $t=1 \mathrm{~s}$;

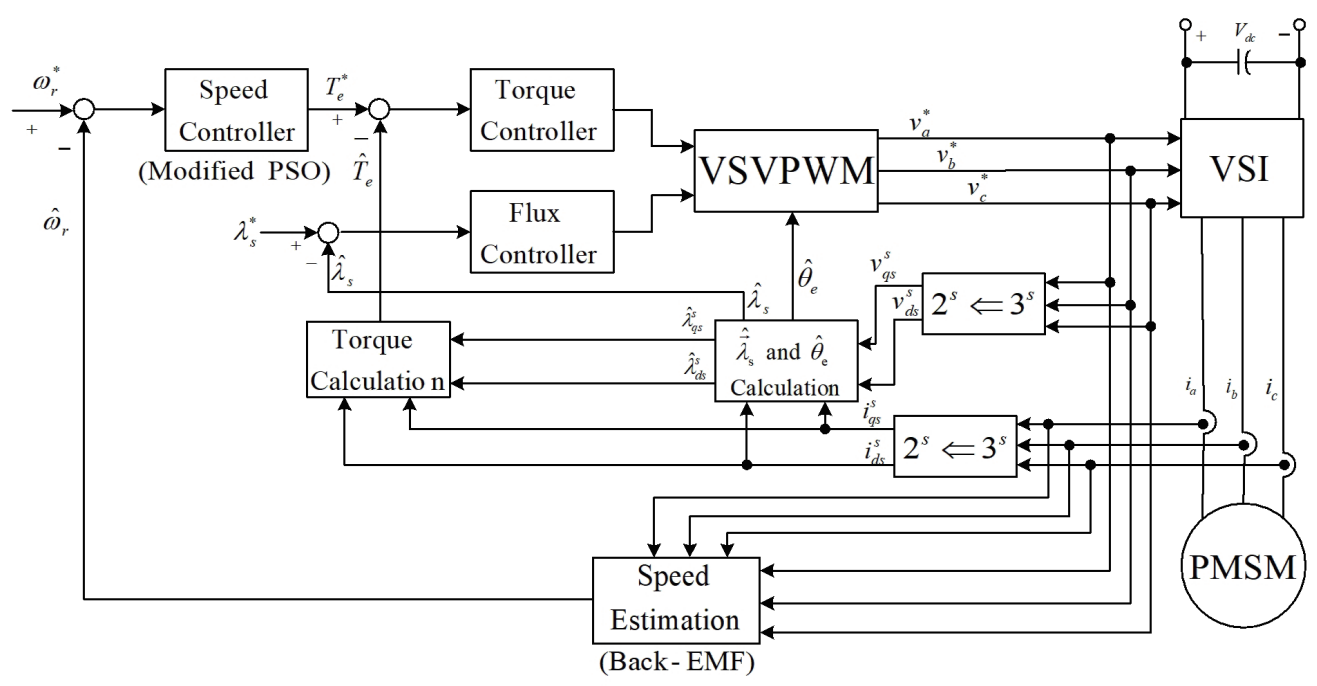

Fig. 7. Speed estimation for DTC PMSM drives based on back-EMF.

Table 1

Controller parameters and bandwidth.

\begin{tabular}{lccc}
\hline Controller type & $K_{p}$ & $K_{i}$ & $B W$ \\
\hline Flux & 28.9 & 5780 & 406 \\
Torque & 1.89 & 1890 & 481 \\
\hline
\end{tabular}




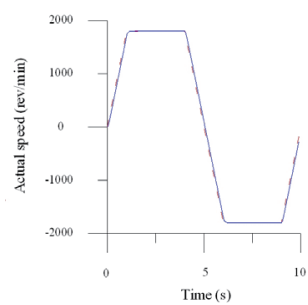

(a)

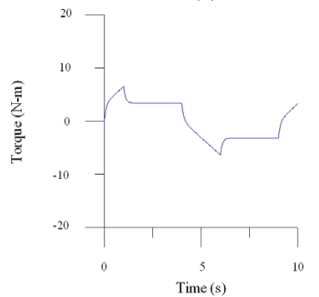

(c)

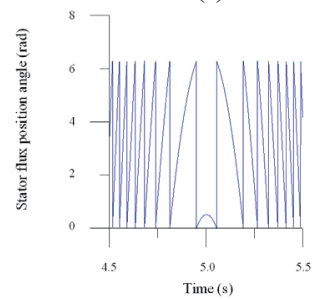

(e)

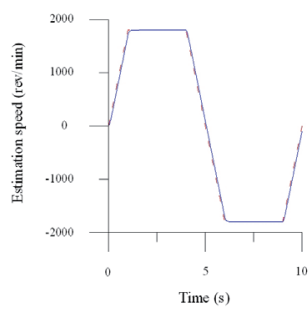

(b)

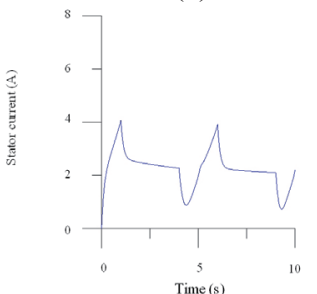

(d)

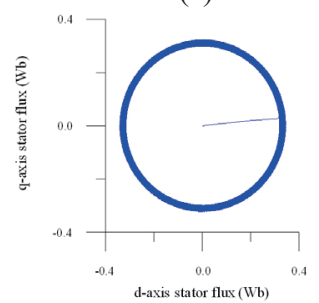

(f)

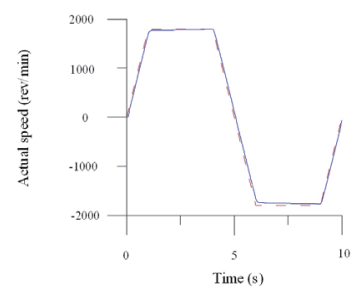

(a)

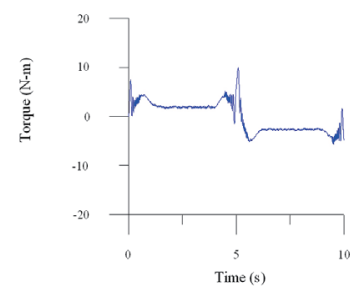

(c)

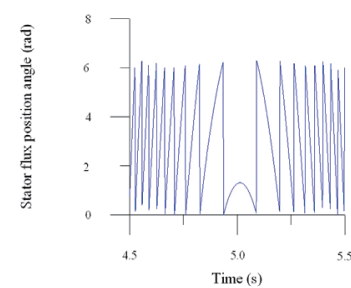

(e)

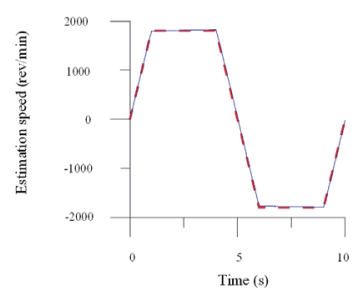

(b)

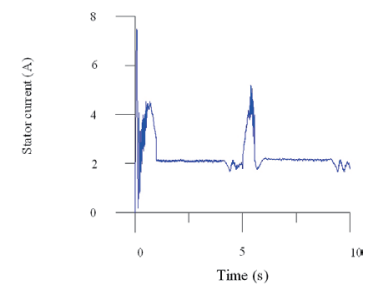

(d)

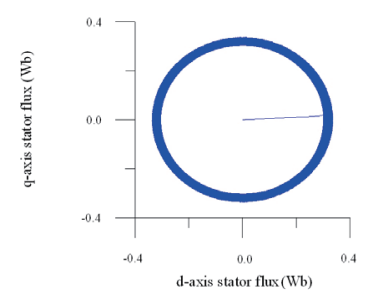

(f)

Fig. 8. (Color online) Simulated responses of the proposed speed estimation DTC PMSM drive based on back-EMF with $2 \mathrm{~N}$-m load for reversible steady-state speed command of $1800 \mathrm{rev} / \mathrm{min}$. (a) Actual rotor speed, (b) estimated rotor speed, (c) electromagnetic torque, (d) stator current, (e) stator flux position angle, and (f) stator flux locus.

Fig. 9. (Color online) Experimental responses of the proposed speed estimation DTC PMSM drive based on back-EMF with $2 \mathrm{~N}-\mathrm{m}$ load for reversible steadystate speed command of $1800 \mathrm{rev} / \mathrm{min}$. (a) Actual rotor speed, (b) estimated rotor speed, (c) electromagnetic torque, (d) stator current, (e) stator flux position angle, and (f) stator flux locus.

forward-direction steady-state running over $1 \leq t \leq 4 \mathrm{~s}$; forward-direction braking to reach zero speed in the interval $4 \leq t \leq 5 \mathrm{~s}$; reverse-direction acceleration from $t=5 \mathrm{~s}$ to $t=6 \mathrm{~s}$; reversedirection steady-state running over $6 \leq t \leq 9 \mathrm{~s}$; reverse-direction braking to reach zero speed in the interval $9 \leq t \leq 10 \mathrm{~s}$.

The simulated and experimental results with $2 \mathrm{~N}-\mathrm{m}$ load for reversible steady-state speed commands of 1800 rev/min are shown in Figs. 8 and 9, respectively. Each figure includes six responses: (a) command (dashed line) and actual (solid line) rotor speed, (b) command (dashed line) and estimated (solid line) rotor speed, (c) electromagnetic torque, (d) stator current, (e) stator flux position angle, and (f) stator flux locus ( $q$-axis vs $d$-axis).

According to the results of the simulated and experimental tests in reversible transient and steady-state operations, the developed speed estimation scheme based on back-EMF could accurately estimate the rotor speed (reversible steady-state command: $1800 \mathrm{rev} / \mathrm{min}$ ) under a load condition. Furthermore, the stator flux position angle and stator flux locus confirmed the exact coordinate transformation to be achieved. 


\section{Conclusions}

An estimated rotor speed scheme based on the back-EMF of a motor was developed to achieve speed estimation for DTC PMSM drives. A DTC PMSM drive was established using stator flux and electromagnetic torque. The established VSVPWM VSI can reduce the ripples of the stator current and electromagnetic torque of DTC PMSM drives. A back-EMF-based rotor position estimator was developed using the three-phase currents and voltages of the stator. The estimated rotor speed was derived from this estimator. A speed controller was designed using a modified PSO algorithm. The three-phase stator currents for implementing the speed estimation method for DTC PMSM drives were provided by Hall effect current sensors. The simulation and experimental results for reversible steady-state speed commands under a load condition confirmed the promising performance of the proposed speed estimation method for DTC PMSM drives.

\section{References}

1 Y. C. Luo, X. H. Zheng, C. H. Liao, and Y. P. Kuo: Sens. Mater. 32 (2020) 1955. https://doi.org/10.18494/ SAM.2020.2785

2 Suryakant, M. Sreejeth, and M. Singh: Proc. 2019 Int. Symp. Advanced Electrical and Communication Technologies (ISAECT 2019) 1-6. https://doi.org/10.1109/ISAECT47714.2019.9069705

3 T. Sharma and A. Bhattacharva: Proc. 2018 2nd Int. Conf. Power, Energy and Environment Towards Smart Technology (ICEPE 2018) 1-6. https://doi.org/10.1109/EPETSG.2018.8659157

4 S. Padhy, C. Subramanian, and Z. Hussian: Proc. 2018 Int. Conf. Power Electronics, Drives and Energy Systems (PEDES 2018) 1-6. https://doi.org/10.1109/PEDES.2018.8707488

5 G. R. Gopinath and S. P. Das: Proc. 2018 Int. Conf. Power Electronics, Drives and Energy Systems (PEDES 2018) 1-6. https://doi.org/10.1109/PEDES.2018.8707900

6 Z. Zhang, R. Tong, and H. Yu: Proc. 2018 IEEE Int. Conf. Mechatronics, Robotics and Automation (ICMRA 2018) 12-16. https://doi.org/10.1109/ICMRA.2018.8490558

7 G. Tian, Y. Yan, W. Jun, Z. Y. Ru, and Z. X. Peng : Proc. 2019 14th IEEE Conf. Industrial Electronics and Applications (ICIEA 2019) 239-245. https://doi.org/10.1109/ICIEA.2019.8833704

8 X. Wang, Z. Wang, Z. Xu, M. Cheng, W. Wang, and Y. Hu: IEEE Trans. Pow Electro. 34 (2019) 6669. https:// doi.org/10.1109/TPEL.2018.2876400

9 A. Ameur, M. Kious, F. Ameur, I. Ameur, and A. Hadjadj: Proc. 2016 8th Int. Conf. Modelling, Identification and Control (ICMIC 2016) 219-224. https://doi.org/10.1109/ICMIC.2016.7804302

10 Q. An, J. Zhang, Q. An, and A. Shamekov: IEEE Trans. Ind. Electro. 67 (2020) 2564. https://doi.org/10.1109/ TIE.2019.2914639

11 D. Bao, X. Pan, Y. Wang, X. Wang, and K. Li: IEEE Trans. Ind. Appl. 54 (2018) 6460. https://doi.org/10.1109/ TIA.2018.2851510

12 R. Sreejith and B. Singh: Proc. IEEE Transportation Electrification Expo. (2019) 1. https://doi.org/10.1109/ ITEC.2019.8790458

13 G. Qiao, M. Wang, F. Liu, Y. Liu, P. Zheng, and Y. Sui: IEEE Trans. Magnetics 55 (2019) 8105006. https://doi. org/10.1109/TMAG.2019.2898888

14 A. Accetta, M. Cirrincione, M. Pucci, and G. Vitale: IEEE Trans. Ind. Electro. 59 (2012) 1355. https://doi. org/10.1109/TIE.2011.2167729

15 Y. C. Luo and W. A. Huang: Low Freq. Noi. Vibr. Act. Contr. 38 (2019) 69. https://doi. org $/ 10.1177 / 1461348418824942$

16 C. H. Liu: Control of AC Electrical Machines (Tunghua, Taipei, 2008) 4th ed., Chap. 5 (in Chinese).

17 M. Z. Youssef, K. Woronowicz, K. Aditya, N. A, Azeez, and S. S. Williamson: IEEE Trans. Power Electro. 31 (2016) 3036. https://doi.org/10.1109/TPEL.2015.2448353

18 L. Ying and N. Ertugrul: IEEE Trans. Power Electro. 18 (2003) 539. https://doi.org/10.1109/TPEL.2003.809377

19 Y. C. Luo and Y. H. Chen: Intel. Fuzz. Sys. 36 (2019) 1215. https://doi.org/10.3233/JIFS-169895 